\section{Lipoprotein(a) as a coronary risk factor in Japanese patients with Type II (non-insulin-dependent) diabetes mellitus. Relation with apolipoprotein(a) phenotypes}

\section{Dear Sir,}

Lipoprotein(a), Lp(a), is a LDL-like lipoprotein particle that contains apo(a), a member of the plasminogen superfamily, covalently linked to apo B100 [1]. Numerous clinical studies have shown that $\mathrm{Lp}(\mathrm{a})$ is an independent risk factor for coronary heart disease $[1,2]$, with some dissent. Type II (non-insulin-dependent) diabetes mellitus is another major risk factor for coronary heart disease [3] and is associated with various coronary risk factors such as dyslipoproteinaemia, hypertension and obesity. Therefore, it is important to define the role of $\mathrm{Lp}(\mathrm{a})$ in association with coronary heart disease and Type II diabetes. Conflicting results have been reported; several reports have shown that $\mathrm{Lp}(\mathrm{a})$ is an independent risk factor [4-9], but others failed to show an association.

Plasma Lp(a) concentrations have large inter-individual variations and at least half of these are attributable to apolipoprotein(a), (apo(a)), size polymorphism [10]. Since apo(a) isoforms are genetically determined, demonstration of their association strongly supports the causal relation, which is difficult to prove when only plasma $\mathrm{Lp}(\mathrm{a})$ concentrations are related to coronary heart disease in case control studies. In this regard, only Ruiz et al. [7] assessed the relation between plasma Lp(a) concentrations, apo(a) phenotypes and coronary heart disease in Type II diabetes of Caucasian patients. They found that raised $\operatorname{Lp}(\mathrm{a})$ concentrations were associated with coronary heart disease and this association was partially accounted for by the increased presence of apo(a) isoforms of small size.

We investigated the relation between plasma $\mathrm{Lp}(\mathrm{a})$ concentrations, apo(a) phenotypes and coronary heart disease in Japanese Type II diabetic patients. We also tested the hypothesis that plasma $\mathrm{Lp}(\mathrm{a})$ concentrations are influenced by glycaemic control or diabetic nephropathy or both, which had been described, albeit controversy, in other studies.

For the study we recruited randomly 270 men with Type II diabetes, aged $59.7 \pm 7.8$ years. We compared 46 patients with coronary heart disease $\left(\mathrm{CHD}^{+}\right)$who had had either a previous

Corresponding author: S. Ishibashi, M.D., Ph. D., Department of Internal Medicine, Faculty of Medicine, University of Tokyo, 7-3-1 Hongo, Bunkyo-ku, Tokyo 113-8655, Japan myocardial infarction, or coronary artery bypass graft surgery, or ischaemic changes in the electrocardiogram with or without exercise, or a combination of these, with 171 patients without coronary heart disease $\left(\mathrm{CHD}^{-}\right)$. We treated 28,101 and 88 patients respectively with insulin, sulphonylurea, and diet alone. Hypolipidaemic drugs such as statins and fibric acid derivatives were given to 181 patients and 85 patients were treated with antihypertensive medication such as calcium channel blockers and angiotensin converting enzyme inhibitors. Plasma $\mathrm{Lp}$ (a) concentrations were determined by enzyme-linked immunosorbent assay. Phenotypes of $\mathrm{Lp}(\mathrm{a})$ were determined by immunoblotting of SDS-polyacrylamide gel electrophoresis and classified according to Kraft et al. [11]. Serum triglycerides, Lp(a) concentrations, and urinary albumin excretion rates were logarithmically transformed before inclusion because the distribution of these values was highly skewed. Student's $t$-test was used for continuous variables. Contingency table chi-square test was used for qualitative traits. KruskalWallis test was used to test the association between apo(a) phenotypes and $\mathrm{Lp}(\mathrm{a})$ concentrations. Logistic regression model was used to determine the independence of the variables which showed relevant association by univariate analyses. Pearson's correlation coefficient was calculated. JMP Version 3 (SAS Institute Inc., N. C., USA) were used for calculations.

Age, duration of diabetes, body mass index, glycated haemoglobin $\left(\mathrm{HbA}_{1 \mathrm{c}}\right)$, systolic blood pressure, diastolic blood pressure, total cholesterol, triglycerides, HDL-cholesterol, Lp(a), urinary albumin excretion rates, smoking habit (non-smoker, smoker, ex-smoker), treatment of diabetes (diet alone, oral hypoglycaemic agents, insulin), hypertension (anti-hypertensive treatment or BP $>160 / 95 \mathrm{~mm} \mathrm{Hg}$ ), hypolipidaemic medication, and macro- or microalbuminuria were compared among $\mathrm{CHD}^{+}$ patients and $\mathrm{CHD}^{-}$patients. Differences were observed for age ( $59 \pm 8$ vs $66 \pm 7$ years; $p<0.01)$, diabetes duration $(15 \pm 8$ vs $22 \pm 9$ years; $p<0.01), \operatorname{Lp}(\mathrm{a})(0.17 \pm 0.18$ vs $0.25 \pm 0.23 \mathrm{~g} / \mathrm{l} ; p<$ $0.01)$, diastolic blood pressure $(74 \pm 9$ vs $70 \pm 9 \mathrm{~mm} \mathrm{Hg} ; p<$ 0.05 ), hypertension (odds ratio $=4.37 ; p<0.001$ ), hypolipidaemic medication (odds ratio $=4.15 ; p<0.01$ ), macro- or microalbuminuria (odds ratio $=4.23 ; p<0.01$ ). $\mathrm{CHD}^{+}$patients showed noticeably lower DBP than $\mathrm{CHD}^{-}$patients, probably because anti-hypertensive medication had been introduced for secondary cardiovascular prevention. Patients with high $\mathrm{Lp}(\mathrm{a})$ concentrations $(>0.30 \mathrm{~g} / \mathrm{l})$ showed higher prevalence of coronary heart disease than those with low $\mathrm{Lp}(\mathrm{a})$ concentrations $(<0.30 \mathrm{~g} / \mathrm{l})$ (odds ratio $=3.43 ; p<0.001)$. Logistic regression analysis was done introducing the coronary risk factors that were identified in univariate analyses $(p<0.01)$. High Lp(a) $(p<0.01)$, old age $(p<0.05)$ and hypolipidaemic medication $(p<0.01)$ seemed to be independent coronary risk factors in our study group. 
Table 1. Frequencies of apo(a) phenotypes and plasma Lp(a) concentrations in Type II diabetic patients with coronary heart disease, $\mathrm{CHD}^{+}$, or without, $\mathrm{CHD}^{-}$

\begin{tabular}{|c|c|c|c|c|c|}
\hline & \multicolumn{2}{|c|}{$\mathrm{CHD}^{-}$} & \multicolumn{2}{|c|}{$\mathrm{CHD}^{+}$} & \multirow[t]{2}{*}{$p$} \\
\hline & $\bar{n}$ & $\begin{array}{l}\mathrm{Lp}(\mathrm{a}) \\
\text { concentrations }\end{array}$ & $\bar{n}$ & $\begin{array}{l}\mathrm{Lp}(\mathrm{a}) \\
\text { concentrations }\end{array}$ & \\
\hline$\overline{\mathrm{BS} 1}$ & 1 & 0.58 & 0 & - & - \\
\hline $\mathrm{F}$ & 1 & 0.23 & 0 & - & - \\
\hline FS3 & 2 & $0.54 \pm 0$ & 0 & - & - \\
\hline FS4 & 1 & 0.51 & 2 & $0.42 \pm 0.04$ & - \\
\hline $\mathrm{S} 1$ & 4 & $0.13 \pm 0.10$ & 2 & $0.15 \pm 0.13$ & NS \\
\hline S1S2 & 2 & $0.40 \pm 0.02$ & 2 & $1.00 \pm 0.16$ & $p<0.05$ \\
\hline S1S3 & 4 & $0.93 \pm 0.06$ & 1 & 0.29 & - \\
\hline S1S4 & 9 & $0.31 \pm 0.20$ & 1 & 0.66 & - \\
\hline S2 & 7 & $0.28 \pm 0.29$ & 0 & - & - \\
\hline $\mathrm{S} 2 \mathrm{~S} 3$ & 4 & $0.19 \pm 0.17$ & 2 & $0.31 \pm 0.30$ & NS \\
\hline $\mathrm{S} 2 \mathrm{~S} 4$ & 4 & $0.36 \pm 0.06$ & 7 & $0.35 \pm 0.07$ & NS \\
\hline S3 & 56 & $0.11 \pm 0.08$ & 16 & $0.16 \pm 0.14$ & NS \\
\hline S3S4 & 26 & $0.17 \pm 0.08$ & 4 & $0.21 \pm 0.11$ & NS \\
\hline S4 & 47 & $0.07 \pm 0.05$ & 9 & $0.12 \pm 0.12$ & NS \\
\hline $\mathrm{O}$ & 3 & $0.02 \pm 0.01$ & 0 & - & - \\
\hline Total & 171 & $0.17 \pm 0.18$ & 46 & $0.25 \pm 0.23$ & $p<0.01$ \\
\hline
\end{tabular}

Mean \pm SD (g/l). The mean values of $\mathrm{Lp}(\mathrm{a})$ were compared by student's $t$-test after $\log _{10}$ transformation. NS; non-significant.

Table 1 shows the frequency distribution of apo(a) isoforms and $\mathrm{Lp}(\mathrm{a})$ concentrations in each apo(a) phenotype subgroup. In both $\mathrm{CHD}^{+}$patients and $\mathrm{CHD}^{-}$patients, large isoforms (designated S3, S3/S4 and S4) predominated. The overall distribution of apo(a) isoforms was displaced towards low molecular mass isoforms in $\mathrm{CHD}^{+}$patients $(p=0.033)$. The frequency of small apo(a) alleles (subjects having either F, B, S1 or S2) was higher in $\mathrm{CHD}^{+}$patients than in $\mathrm{CHD}^{-}$patients (odds ratio $=1.98 ; p=0.052)$. In both groups the differences in $\mathrm{Lp}(\mathrm{a})$ concentrations among apo(a) phenotypes were highly significant (Kruskal-Wallis test: $\chi^{2}=77.4 ; p<0.0001$ for $\mathrm{CHD}^{-}$patients and $\chi^{2}=22.6 ; p<0.01$ for $\mathrm{CHD}^{+}$patients). There is an inverse association of apo(a) size with $\mathrm{Lp}(\mathrm{a})$ concentrations. In each phenotype subgroup, $\mathrm{CHD}^{+}$patients tended to have higher $\mathrm{Lp}(\mathrm{a})$ concentrations than $\mathrm{CHD}^{-}$patients, but the difference was not statistically significant.

Neither $\mathrm{HbA}_{1 \mathrm{c}}(r=0.02 ; p=0.82)$ nor urinary albumin excretion rates $(r=0.02 ; p=0.84)$ were correlated significantly with plasma $\mathrm{Lp}(\mathrm{a})$ concentrations.

In conclusion, we have confirmed that increased plasma $\mathrm{Lp}(\mathrm{a})$ concentrations are a strong independent coronary risk factor in our Japanese study group of Type II diabetic patients. Furthermore, the association between the high Lp(a) concentrations and coronary heart disease is partly accounted for by the increased presence of small apo(a) isoforms. To prevent future coronary heart disease in Type II diabetic patients efforts should be directed at screening diabetic patients for high $\mathrm{Lp}$ (a) concentrations and a vigorous management of coronary establishing risk factors in these patients.

Yours sincerely,

K. Murakami, S. Ishibashi, Y. Yoshida, N. Yamada, Y. Akanuma

\section{References}

1. Utermann G (1995) Lipoprotein(a). In: Scriver CR, Beau$\operatorname{det}$ AL, Sly WS, Valle D (eds) The metabolic and molecular basis of inherited disease, 7 th edn. McGraw-Hill, New York, pp 1887-1912

2. Scanu A, Lawn RM, Berg K (1991) Lipoprotein(a) and atherosclerosis. Ann Intern Med 115: 209-218

3. Kannel W, McGee DL (1979) Diabetes and cardiovascular diseases: the Framingham study. JAMA 241: 2035-2038

4. Heesen BJ, Wolffenbuttel BH, Leurs PB et al. (1993) Lipoprotein(a) levels in relation to diabetic complications in patients with non-insulin-dependent diabetes. Eur J Clin Invest 23: 580-584

5. Ruiz J, Thillet J, Huby Tet al. (1994) Association of elevated lipoprotein(a) levels and coronary heart disease in NIDDM patients. Relationship with apolipoprotein(a) phenotypes. Diabetologia 37: 585-591

6. Hiraga T, Kobayashi T, Okubo M et al. (1995) Prospective study of lipoprotein(a) as a risk factor for atherosclerotic cardiovascular disease in patients with diabetes. Diabetes Care 18: 241-244

7. James RW, Boemi M, Sirolla C, Amadio L, Fumelli P, Pometta D (1995) Lipoprotein(a) and vascular disease in diabetic patients. Diabetologia 38: 711-714

8. Jenkins AJ, Best JD (1995) The role of lipoprotein(a) in the vascular complications of diabetes mellitus. J Intern Med 237: 359-365

9. Watts GF, Gwilym RM, Mazurkiewicz J, Coltart J (1995) Independent correlation between plasma lipoprotein(a) and angiographic coronary artery disease in NIDDM. Diabetes Care 18: 234-236

10. Utermann G, Menzel HJ, Kraft HG, Duba HC, Kemmler HG, Seitz C (1987) Lp(a) glycoprotein phenotype: inheritance and relation to $\mathrm{Lp}(\mathrm{a})$-lipoprotein concentrations in plasma. J Clin Invest 80: 458-465

11. Kraft H, Dieplinger H, Hope E, Utermann G (1988) Lp(a) phenotyping by immunoblotting with polyclonal and monoclonal antibodies. Atherosclerosis 8: 212-216

Diabetologia (1998) 41: 1397-1398 